\title{
Oestrogen blocks the nuclear entry of SOX9 in the developing gonad of a marsupial mammal
}

\author{
Andrew J Pask ${ }^{1,2^{*}}$, Natalie E Calatayud ${ }^{2}$, Geoff Shaw ${ }^{2}$, William M Wood ${ }^{1}$, Marilyn B Renfree ${ }^{2}$
}

\begin{abstract}
Background: Hormones are critical for early gonadal development in nonmammalian vertebrates, and oestrogen is required for normal ovarian development. In contrast, mammals determine sex by the presence or absence of the $S R Y$ gene, and hormones are not thought to play a role in early gonadal development. Despite an XY seXdetermining system in marsupial mammals, exposure to oestrogen can override SRY and induce ovarian development of $X Y$ gonads if administered early enough. Here we assess the effect of exogenous oestrogen on the molecular pathways of mammalian gonadal development.

Results: We examined the expression of key testicular (SRY, SOX9, AMH and FGF9) and ovarian (WNT4, RSPO1, FOXL2 and FST) markers during gonadal development in the marsupial tammar wallaby (Macropus eugenii) and used these data to determine the effect of oestrogen exposure on gonadal fate. During normal development, we observed male specific upregulation of $A M H$ and SOX9 as in the mouse and human testis, but this upregulation was initiated before the peak in SRY expression and 4 days before testicular cord formation. Similarly, key genes for ovarian development in mouse and human were also upregulated during ovarian differentiation in the tammar. In particular, there was early sexually dimorphic expression of FOXL2 and WNT4, suggesting that these genes are key regulators of ovarian development in all therian mammals. We next examined the effect of exogenous oestrogen on the development of the mammalian XY gonad. Despite the presence of SRY, exogenous oestrogen blocked the key male transcription factor SOX9 from entering the nuclei of male somatic cells, preventing activation of the testicular pathway and permitting upregulation of key female genes, resulting in ovarian development of the XY gonad.

Conclusions: We have uncovered a mechanism by which oestrogen can regulate gonadal development through the nucleocytoplasmic shuttling of SOX9. This may represent an underlying ancestral mechanism by which oestrogen promotes ovarian development in the gonads of nonmammalian vertebrates. Furthermore, oestrogen may retain this function in adult female mammals to maintain granulosa cell fate in the differentiated ovary by suppressing nuclear translocation of the SOX9 protein.

See commentary: http://www.biomedcentral.com/1741-7007/8/110
\end{abstract}

\section{Background}

During vertebrate evolution, there has been a distinct switch from a strong hormonal influence on sex determination to a genetic switch mechanism. In nonmammalian vertebrates, oestrogen administration to male embryos, or blocking oestrogen production in female embryos, results in sex reversal [1]. In contrast, in mice, oestrogen does not affect the early development of

\footnotetext{
* Correspondence: andrew.pask@uconn.edu

'Department of Molecular and Cellular Biology, University of Connecticut, Storrs, CT 06260, USA

Full list of author information is available at the end of the article
}

either ovaries or testes, and in its absence, gonadal development proceeds normally until after birth [2]. Although the role of oestrogen in determining gonadal fate differs between vertebrates, the downstream pathways of gonadal differentiation are highly conserved. In particular, SOX9, the key regulator of testicular differentiation, appears to have similar functions in all vertebrates [3], starting with cytoplasmic expression in the indifferent gonad, but translocating to the nucleus in males to activate the testicular pathway [4-6]. In oestrogen-deficient female mice (made by deletion of one or both oestrogen receptor genes or of the Cyp19A1 gene 
that encodes the aromatase enzyme), germ cells are gradually lost from pubertal ovaries concomitant with remodeling of the somatic tissue. There is also transdifferentiation of the ovarian granulosa cells to form testicular Sertoli-like cells that express SOX9 and align in structures resembling testicular cords [7]. This phenotype can be reversed by administration of oestrogen, causing the somatic cells to reform granulosa cells and resulting in an ovarian architecture and suppression of SOX9 [7]. These data show that although oestrogen is not required for early ovarian development in mice, it is critical for maintaining ovarian somatic cell fate in the differentiated gonad.

How and why oestrogen became dissociated from sex determination in mammals is unknown. A genetically controlled sex determination mechanism may have evolved in mammals to protect the young developing in utero from the effect of large quantities of oestrogen in the fetoplacental unit [8,9]. However, oestrogen receptor expression is maintained in the indifferent mammalian gonad [10,11] despite their apparent lack of function, and exposure of gonads to exogenous oestrogen activates the translocation of the receptors to the nuclei of indifferent gonadal cells [12]. Not surprisingly, the mammalian placenta is highly effective in metabolizing hormones before they reach the developing fetus [13], protecting it from maternal influences. Marsupial mammals are born with undifferentiated gonads that undergo gonadal sex determination postnatally [14], allowing daily administration of oestrogen directly to developing male young from before the testis pathway is initiated. Oestrogen treatment of XY young in the opossum and in the tammar wallaby directs the development of the indifferent gonads towards an ovarian differentiation fate [15-21], including entry of the XY germ cells into meiosis, despite the presence of a Y-chromosome and $S R Y[17-19,21]$.

The sex-reversing effects of exogenous oestrogen on the marsupial XY gonad are time-dependent $[17,18]$, just as there is a critical time window of Sry action in the mouse [22]. Complete ovarian formation with germ cells arrested in meiosis was seen only in animals that were born about 1 day prematurely in a 26.5-day pregnancy in the tammar $[18,21]$ and one half to 1 day prematurely in the 13.5-day gestation in the opossum [17]. Treatment of animals born after a full-term pregnancy with the same dose of oestrogen did not affect testicular development and resulted in only minor disruption of the testis in both species [17-19].

These findings suggest that there is a critical point in development when the XY gonad becomes irreversibly committed to a testicular fate. In the tammar, this coincides with the first morphological signs of Sertoli cell development and seminiferous cord formation, which occurs after birth from a normal full-term pregnancy [14]. To promote ovarian development, oestrogen must be administered before the somatic cell lineage has initiated Sertoli cell development. Early experiments treating opossums with large amounts of androgens did not affect gonadal development of male or female young $[15,16]$. Similarly, in the tammar, testosterone administration to male pouch young had no visible effect on testicular structure, although oestrogen given after testes development was initiated did cause a small degree of testicular dysgenesis [20]. Identical findings have also been reported in nonmammalian vertebrates in which administration of oestrogen to the indifferent gonad can actively induce ovarian development, independent of genetic or environmental sex-determining factors $[1,23]$, whereas exogenous androgen treatment does not affect testicular development [23]. The effects of oestrogen are mediated through the oestrogen receptors (ERs) in the gonad [2]. Treatment of the tammar XY gonads at day 25 of gestation with oestrogen in culture causes the oestrogen receptors to move from a cytoplasmic to nuclear localization within the cell, consistent with their activation and ability to affect gene transcription in an oestrogen-dependent manner [12]. The nuclear translocation of both receptor proteins in the presence of exogenous oestrogen in culture confirms the ability of the receptors to respond functionally to the ligand, even at early developmental stages [12]. Thus the observed effects of exogenous oestrogen are oestrogen-, and not steroid-, specific

The genes controlling sex determination are conserved between eutherian and marsupial mammals. SRY and SOX9 are expressed in the developing Sertoli cells of the XY eutherian and marsupial testis [4,24,25]. These cells direct the development of the testicular architecture and secrete $\mathrm{AMH}$, a hormone necessary for the regression of the Müllerian ducts [26-28]. In the absence of $S R Y$ in developing XX gonads, SOX9 levels are significantly lower $[4,25], A M H$ is not activated and the Müllerian ducts remain intact [26,27]. FGF9 may also be important for Sertoli cell specification [29] and shares an antagonistic relationship with an ovarian differentiation gene, WNT4 [30]. Other key ovarian development genes include FOXL2, RSPO1 and FST, which are upregulated in the somatic cells of the early developing ovary in mice and humans [31-33]. Disruption of each gene dramatically affects ovarian differentiation and can lead to varying degrees of testicular development in XX mammals [31-33].

To determine the molecular changes occurring during oestrogen -induced sex reversal of XY gonads, we investigated the expression of key male and female differentiation factors (SRY,SOX9, AMH and FGF9 and key ovarian markers FOXL2, FST, RSPO1 and WNT4) in our 
model marsupial, the tammar wallaby, during the critical period of gonadal differentiation and after oestrogeninduced sex reversal. Here we show that exposure of the indifferent $\mathrm{XY}$ gonad to oestrogen resulted in suppression of $S R Y$ and $A M H$ and upregulation of FOXL2 and WNT4, thus diverting the male developmental pathway into the female one. The SOX9 gene was not downregulated by oestrogen exposure during XY ovarian development, but SOX9 protein was prevented from entering the nucleus of the supporting cells in the presence of oestrogen and therefore could not activate the male developmental program. We hypothesise that this novel function of oestrogen in modulating the nucleocytoplasmic localization of SOX9 may reflect an ancestral primordial mechanism by which oestrogen mediates sex determination in nonmammalian development. However, oestrogen retains an important function in adult female mammals by maintaining granulosa cell fate in the differentiated ovary by suppressing nuclear localization of the SOX9 protein.

\section{Results}

Molecular development of the marsupial gonad mirrors that of the eutherian gonad

We used quantitative polymerase chain reaction (qPCR) to examine the normal expression profiles of key male and female gonadal differentiation genes during early testicular and ovarian development from day 25 of gestation ( -1 day relative to birth) through day 10 postpartum in the tammar wallaby ( $n \geq 5$ per sex per stage). The molecular control of testicular development in the developing tammar was similar to that of the mouse and human, except that the first signs of sexually dimorphic expression of $S O X 9$ and $A M H$ preceded the peak in $S R Y$ expression and testicular differentiation. $S R Y$ (Fig. 1a) expression increased from day 24 of gestation ( -2 days relative to birth) in XY gonads and reached a peak at day 1 postpartum (pp) around the time of testicular cord formation. SRY levels then fell sharply as in the mouse [34,35] and human [36]. In tammar males, SOX9 (Fig. 1b) rose in the gonad, initially in concert with $S R Y$, but continued to increase after $S R Y$ expression fell, consistent with its suggested autoregulation [37]. SOX9 was significantly higher in males than in females from day 24 of gestation $(P=0.001$; Additional File 1), 4-5 days before the onset of testis cord formation, consistent with its activation by $S R Y$ binding to the conserved testis-specific enhancer element TESCO in the $S O X 9$ promoter, that is found in marsupials as well as in eutherians [3,37]. In female gonads, SOX9 levels declined relative to levels in the testes, presumably due to the absence of $S R Y$. SOX9 levels were lowest in females at day 1-2 pp (the time of cord formation in testes) and remained consistently lower in the ovary throughout development. $A M H$ expression (Fig. 1c) was identical at day 24 of gestation in $\mathrm{XX}$ and $\mathrm{XY}$ gonads, but became significantly lower in ovaries $(P=0.0002$; Additional File 1) by day 26 of gestation, the day of birth. The sexual dimorphism in $A M H$ expression is consistent with reduced $S O X 9$ expression in $\mathrm{XX}$ compared to XY gonads by day 26 of gestation $(P=0.0001)$. $A M H$ levels remained significantly lower in ovaries than in testes throughout the period of development examined. FGF9 expression (Fig. 1d) was unexpectedly higher in females than in males during very early testis cord formation (days 1-3 pp; $P<0.01$ ) but reached peak expression above that seen in the ovary by day $4 \mathrm{pp}(P$ $<0.01)$. This is concomitant with a drop in WNT4 expression at this stage (Fig. 1h), further supporting an antagonistic interaction between these two genes in the gonad [30]. FOXL2 (Fig. 1e) was significantly lower in males than in females over the entire period examined $(P<0.01)$, consistent with expression seen in the developing mouse gonads [38], which suggests a conserved early role for this gene in mammalian ovarian development. FST expression (Fig. 1f) was not significantly lower in developing testes than in ovaries during early development but became significantly upregulated in developing ovaries after day $5 \mathrm{pp}(P<0.004)$ during the time of ovarian differentiation. RSPO1 (Fig. 1g) was not significantly lower in males than in females during early gonadal development. However, on day $4 \mathrm{pp}$, RSPO1 levels dropped in females and were significantly higher in males $(P<0.007)$. After day $4 \mathrm{pp}$, levels dropped in males and increased in females during the key window of ovarian differentiation. WNT4 expression (Fig. 1h) was generally higher in females than in males but this was only significant after day $4 \mathrm{pp}$, again during the time of active ovarian differentiation, as seen for FST and RSPO1. $P$ values were significantly different at almost all time points for FOXL2, FST, AMH and SOX9 (Additional File 1).

\section{Exogenous oestrogen causes development of ovarian structures in $\mathrm{XY}$ gonads}

To verify that exogenous oestrogen would cause gonadal sex reversal in culture as it does in vitro [18], we examined the histological organization of the gonads from two control and two oestrogen-treated XY gonads after incubation in either control or oestrogen-supplemented media. Gonads were collected at day 25 of gestation, just before gonadal sex determination and birth. Gonads placed in control media and grown for 5 days had normal testicular architecture with the formation of seminiferous cords lined with Sertoli cells, encapsulating the germ cells (Fig. 2, top). Conversely, XY gonads cultured in the presence of oestrogen did not develop testicular cords and instead the gonads took on an ovarian 


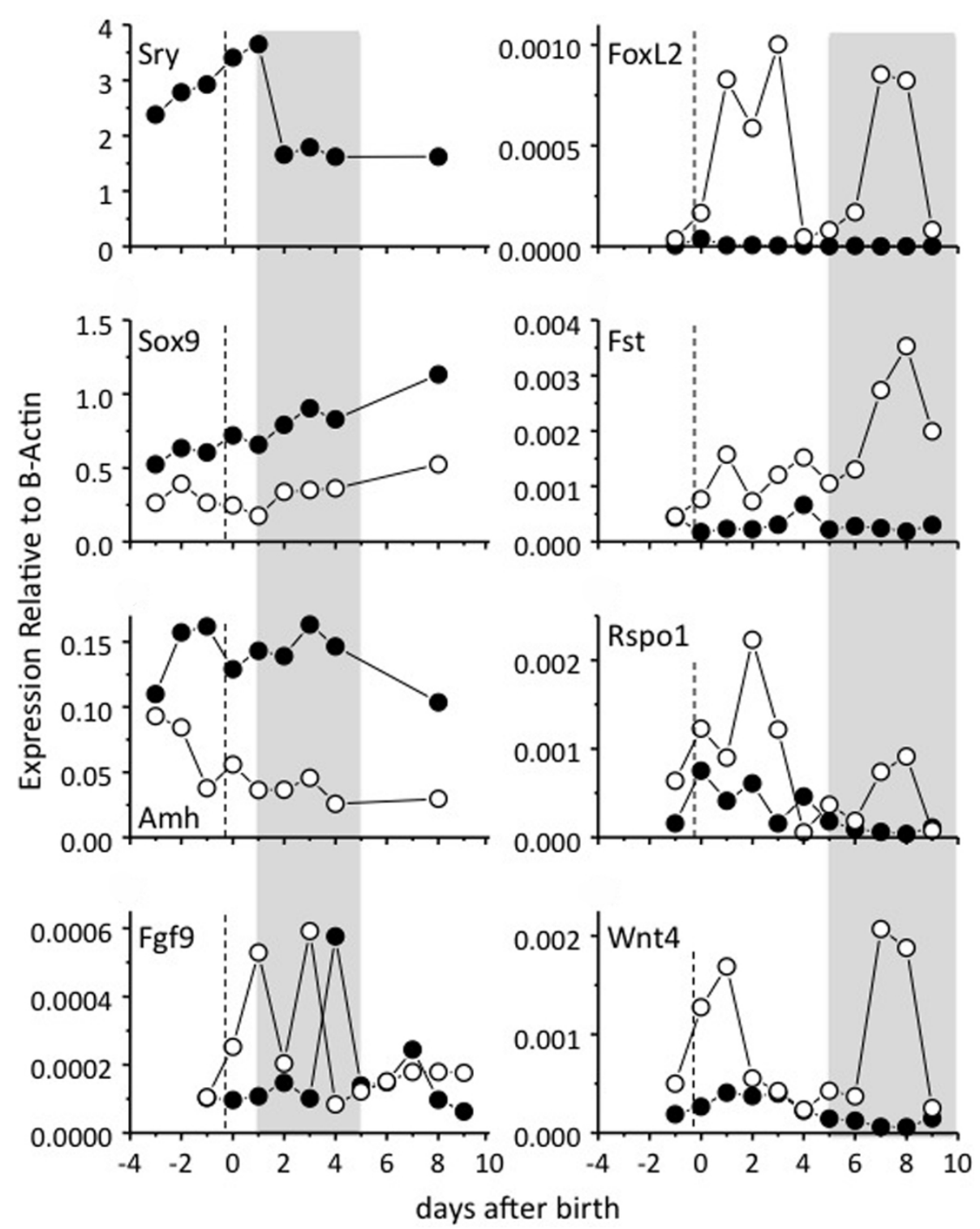

Figure 1 Quantitative mRNA expression for SRY, SOX9, AMH, FGF9, FOXL2, FST, RSPO1 and WNT4 during normal male (solid circles) and female (open circles) gonadal differentiation. Dotted line indicates day of birth, grey shading in a-d indicates the period of testis patterning and grey shading in e-h indicates the window of ovarian patterning. The critical period of testicular differentiation occurs between day 25 of gestation and day 2 postpartum, and that of ovarian differentiation between days 6-10 postpartum. $P$ values from $t$-tests conducted to examine whether expression levels of the various genes were significantly different between males and females at each data point are shown in Additional file 1. Raw data for the mean $\Delta \mathrm{Ct}$ and standard deviations for each data point are shown in Additional file 5.

appearance, with the formation of a clear demarcation between the cortex and medulla (Fig. 2, bottom).

\section{Exogenous oestrogen has a dramatic effect on the} testicular differentiation pathway

We next investigated the effect of sex reversal on the expression of key testicular genes in 10 pairs of null control and oestrogen-treated XY gonadal cultures by quantitative PCR. In the control gonads, the levels of SRY, SOX9 and AMH were comparable to those in vivo, demonstrating that the gonads developed normally in culture. However, the mRNA levels of both $S R Y(P<$ $0.001)$ and $A M H(P<0.001)$ were significantly reduced in $\mathrm{XY}$ gonads cultured in the presence of oestrogen (Fig. 3a, Additional file 2). FGF9 levels were also suppressed in oestrogen-treated gonads, although levels were not significant $(P<0.06$; Additional file 2$)$. In contrast, SOX9 mRNA levels did not differ significantly $(P>0.5)$ as a result of the treatment (Fig. 3a), despite the development of ovarian architecture. This was unexpected 


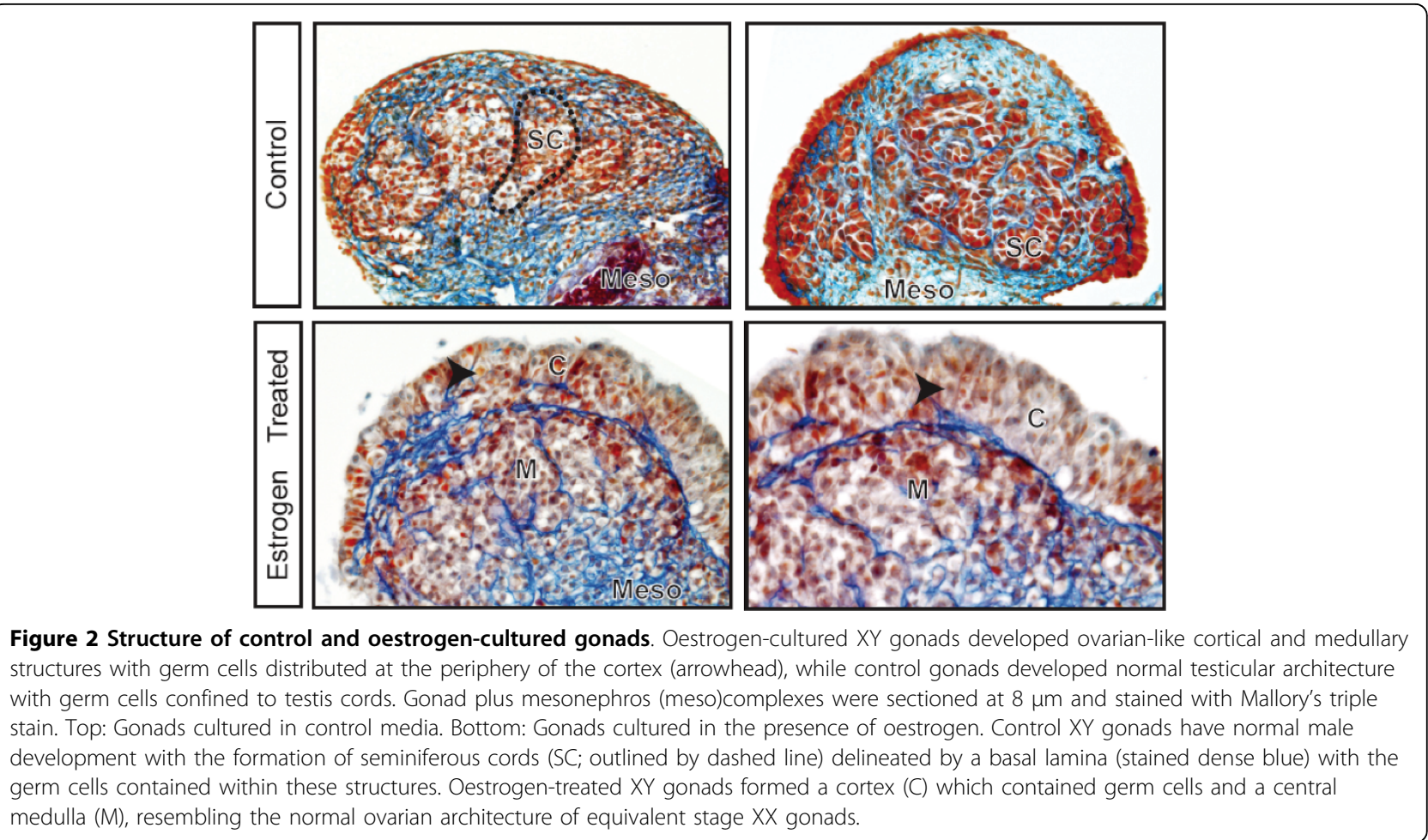

because SOX9 upregulation induces testis formation in eutherian mammals $[39,40]$.

\section{SOX9 protein remains cytoplasmic in the presence of oestrogen}

As a transcription factor, it is not just the level of SOX9, but also its subcellular localization that is essential for its function in initiating testicular development [4]. We therefore investigated SOX9 protein distribution using immunocytochemistry in two control and two oestrogen-treated XY gonads. In control XY gonads, SOX9 was almost entirely nuclear and restricted to the Sertoli cells of the developing testis, consistent with its distribution seen during normal in vivo development [25] (Figs. $4 \mathrm{a}$ and $4 \mathrm{~b})$. However, XY gonads cultured in the presence of oestrogen had diffuse SOX9 staining that was restricted to the cytoplasm of gonadal cells and did not enter the nuclei (Figs. 4c and 4d). Since SOX9 levels were sexually dimorphic before gonadal differentiation, we also investigated protein distribution at day 25 of gestation (the first day of culture). At this stage, SOX9 had a strong cytoplasmic distribution but had become nuclear in a subset of somatic cells (Additional file 3).

\section{Exogenous oestrogen activates the female differentiation pathway}

In addition to the downregulation of testicular genes, oestrogen exposure and lack of nuclear SOX9 in the tammar sex-reversed XY gonads led to an upregulation of the key ovarian differentiation genes FOXL2 $(P<$ $0.004)$ and $\operatorname{WNT4}(P<0.02)$ (Fig. 3b, Additional file 1$)$, consistent with findings that both genes are critical early regulators of ovarian development $[31,33,38]$. In tammar sex-reversed gonads, FGF9 was downregulated in concert with WNT4 upregulation, supporting a conserved antagonistic interaction between these two genes in mammalian gonadal differentiation [30]. RSPO1 was significantly downregulated $(P<0.001)$ in the presence of oestrogen, consistent with the normal expression of this gene at day $4 \mathrm{pp}$ in males and females, suggesting that at this stage of development, RSPO1 is not required for marsupial ovarian differentiation. FST mRNA expression was not significantly altered by oestrogen treatment $(P>$ 0.5; Fig. $3 \mathrm{~b}$ and Additional file 2).

\section{Discussion}

Marsupials occupy a unique evolutionary niche and can provide important information on the evolution and conservation of mammalian developmental pathways. This is the first comprehensive study of the expression levels of key testicular and ovarian genes during gonadogenesis in any marsupial. During normal development in the tammar gonad, expression of key male development genes is similar to that seen in the mouse and human, except that $A M H$ and SOX9 show sexually dimorphic gene expression before the peak in SRY expression at 

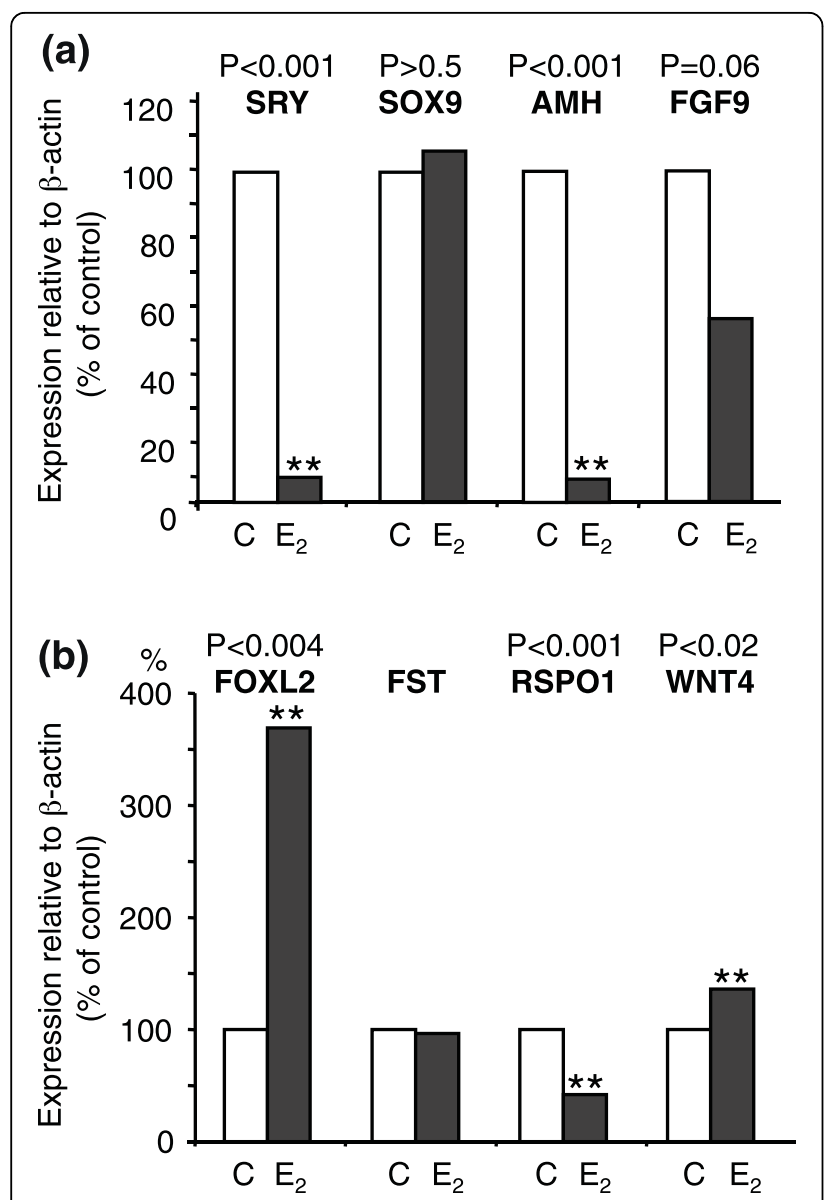

Figure 3 Gene expression in $X Y$ oestrogen-treated gonads cultured from day $\mathbf{2 5}$ of gestation for $\mathbf{5}$ days. Quantitative $P C R$ for key male markers SRY, SOX9, AMH and FGF9 (a), and key female markers FOXL2, RSPO1, WNT4 and FST (b) during gonadal culture in control (open bars) and oestrogen-treated (black bars) gonads. Both SRY and AMH mRNA levels were significantly suppressed $(P<0.001)$ in the sex-reversed gonads. However, SOX9 mRNA levels were unchanged $(P>0.5)$. There was significant upregulation of the ovarian genes FOXL2 $(P<0.004)$ and WNT4 $(P<0.02)$ in sexreversed gonads, while FST was unchanged and RSPO1 was significantly downregulated $(P<0.001)$ in the presence of oestrogen.

day $1 \mathrm{pp}$. Furthermore, SOX 9 has already begun its nuclear translocation 3 days before the peak in $S R Y$ expression and the appearance of testicular cords. This may be the result of the long period of $S R Y$ expression seen in marsupials [24], similar to that of human XY gonads [36] but different from the ultrashort pulse seen in mice [34,35]. The key female development genes FOXL2 and WNT4 were upregulated in the XX gonad during the time of ovarian development (5-10 days pp). However, RSPO1 and FST expression was variable in the early gonad, and female-specific upregulation was seen only during the later stages of ovarian development. This observation suggests that these two genes act downstream of FOXL2 and WNT4 in the ovarian differentiation pathway, at least in the tammar.

Cultured XY control gonads had normal male expression profiles and formed testicular cords. However, XY gonads cultured in the presence of oestrogen failed to upregulate $S R Y$ and $A M H$ expression and instead upregulated FOXL2 and WNT4. The oestrogen-exposed XY gonads also developed ovarian architecture, confirming that female development had occurred. Surprisingly, mRNA levels for SOX9, the key factor essential for testicular development, did not differ between control and treated XY gonads, despite ovarian development. To investigate this further, we examined the protein localisation of SOX9 in control and oestrogen-treated XY gonads. Since SOX9 is a transcription factor, nuclear localisation is essential to activate the male developmental program and SOX9 mutations that affect nuclear import result in XY sex reversal in humans [41,42]. In the mouse and human, the SOX9 protein is initially cytoplasmic in the indifferent gonad of both $\mathrm{XX}$ and $\mathrm{XY}$ fetuses, but becomes rapidly nuclear and upregulated only after the peak of $S R Y$ expression in testes, whereas in ovaries, Sox9 remains cytoplasmic and is lost [4,5]. In the clawed toad, Xenopus, SOX9 also remains cytoplasmic in developing ovaries but becomes nuclear under testis-promoting conditions in the absence of oestrogen and is upregulated $[6,43]$. However, in the presence of oestrogen under ovary-promoting conditions, SOX9 remains cytoplasmic and is downregulated.

In mice, Sry initiates Sox 9 upregulation within preSertoli cells. Sox9 then autoregulates to reach threshold levels that activate testicular development [44]. In the tammar, SRY had initiated SOX9 upregulation before the cultures began (Fig. 1; Additional file 1) and before the peak in $S R Y$ expression 3 days later. Thus oestrogen exposure at this time (day 25 of gestation) did not prevent the initial wave of SOX9 mRNA upregulation, but the protein was restricted to the cytoplasm of somatic cells, preventing its activation of the male pathway and likely its self-propagated upregulation. This observation explains the initiation of ovarian development in the treated XY gonads in this in vitro study and in the earlier in vivo studies $[17,18,21]$. Treatment of developing turtle gonads with oestrogen at stages of development before gonadal sex determination had occurred (and prior to the initial upregulation of SOX9) prevented SOX9 from becoming upregulated to equivalent male or even female levels [45]. These findings suggest that there is also a direct action of oestrogen in repressing SOX9 transcription in turtles, as we have observed in the tammar. Interestingly, in the turtle, SOX9 protein is nuclear in female gonads before sex determination. We see a similar nuclear localization in the indifferent gonad in the tammar wallaby (Additional file 3). 


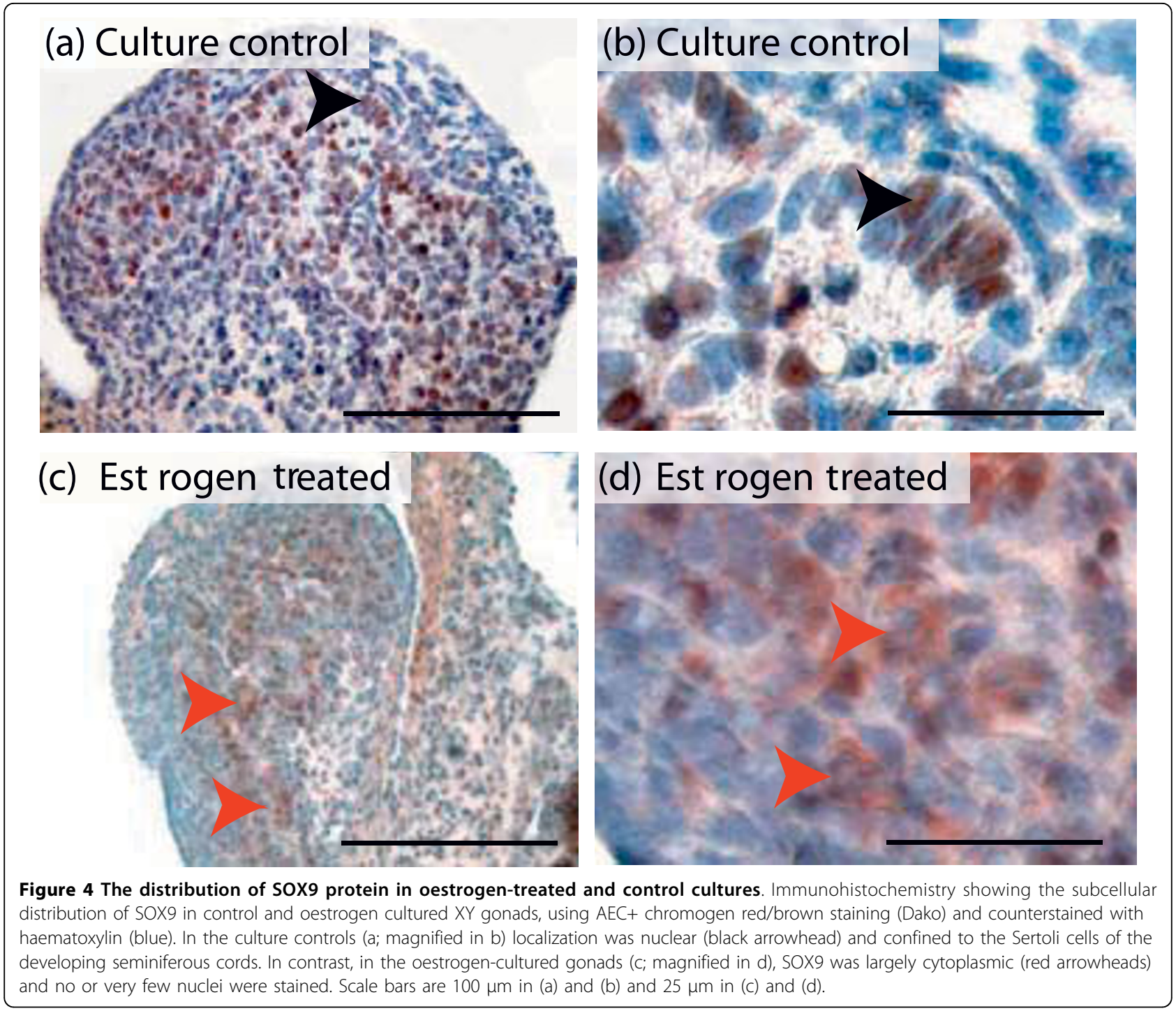

We hypothesize that in the absence of hormones at early stages of gonadal development, SOX9 can feely translocate to the nucleus of somatic cells. In mammals, SOX9 expression is reinforced by SRY, upregulating it above threshold levels enabling it to autoregulate and initiate testicular development. In nonmammalian vertebrates, the oestrogen production could act to directly suppress SOX9 upregulation and promote ovarian development. Our results show that oestrogen restricts translocation of the SOX9 protein, forcing it to remain in the cytoplasm and prevent its self-propagated upregulation. Since SOX9 mRNA is never elevated above basal levels in the oestrogen-treated male turtle, the effect of oestrogen on its subcellular localization cannot be observed in their gonads. However, in our study, we administered oestrogen slightly later in development, just after the initial wave of SOX9 upregulation. Our results therefore highlight a mechanism by which oestrogen could prevent testicular development (Fig. 4). The exclusion of SOX9 from somatic cell nuclei of the oestrogen cultured gonads is further confirmed by the failure of $A M H$ upregulation because in the mouse, Sox 9 acts as a nuclear transcription factor to drive Amh expression [46].

In the absence of nuclear SOX9 in XY oestrogen-treated gonads, female development was initiated. FOXL2 was significantly upregulated, consistent with an early and essential role for this gene in initiating ovarian development in mammals. In goats, FOXL2 induces aromatase (CYP19) expression, leading to oestrogen production in the developing ovary [38]. This mechanism could potentially ensure a block in male development by excluding SOX9 nuclear entry. This mechanism could work in synergy with activated ERs to facilitate FOXL2 binding to TESCO, further suppressing SOX9 mRNA 
production as recently suggested in goats [38]. However, the oestrogen response elements contained within the mouse TESCO element [37] do not fall into the evolutionarily conserved regions identified in most vertebrates [3], suggesting that this mechanism of oestrogen action may not be as important as its role to prevent SOX9 from entering the nucleus.

Several lines of evidence demonstrate that oestrogen acts as a modulator of the subcellular localization of SOX9. Sox9 is produced at a low level in the somatic cells of the adult mouse ovary [47], but its self-propagated upregulation is somehow blocked. Our findings suggest that circulating oestrogen could prevent the nuclear translocation of SOX9 in differentiated ovarian somatic cells, thus preventing its own upregulation. In the absence of oestrogen in female aromatase-deficient knockout mice, Sox9 is upregulated in ovarian somatic cells, as it can presumably translocate to the nucleus to propagate its own transcription. However, when exogenous oestrogen is administered to aromatase-deficient mice, this effect is reversible and Sox9 is repressed [5,48]. This mechanism therefore explains how Sox9 upregulation is able to occur in the oestrogen-deficient mouse ovary and how it can be subsequently suppressed with somatic cell transdifferentiation in the presence of exogenous oestrogen. These findings suggest that in mammals, oestrogen may still be a critical factor regulating ovarian somatic cell fate maintenance by preventing SOX9 nuclear translocation.

This fundamental role of oestrogen can explain its sex-determining ability in nonmammalian vertebrates. SOX9 remains cytoplasmic in the developing ovaries of nonmammalian vertebrates in the presence of oestrogen [5]. However, in the absence of oestrogen, SOX9 becomes nuclear and testicular development is initiated [41]. Our findings suggest that this may be a universal action of oestrogen in all vertebrates.

How oestrogen prevents SOX9 from entering the nucleus is still unknown. There are several known pathways that control SOX9 nuclear entry, such as altered importin- $\beta 1$ or calmodulin binding, both of which facilitate effective transport of SOX9 across the nuclear pore complex $[41,42]$. In addition, sumoylation and/or ubiquitination also affect the subcellular localization and transcriptional activity of SOX9 $[49,50]$. Oestrogen is known to directly affect sumoylation and the subcellular localization of the nuclear receptor coactivator family member 3 protein in breast cancer cell lines [51]. Oestrogen may work in a similar way in the gonad by modulating sumoylation and/or ubiquitination of the SOX9 protein, trapping it in the cytoplasm.

\section{Conclusions}

We have uncovered a mechanism using a marsupial model that provides a link between mammalian and nonmammalian vertebrate sex determination mechanisms (Fig. 5). We have shown that exogenous oestrogen can inhibit the nuclear translocation of SOX9, blocking testicular development in an XY mammalian gonad. As a result, ovarian differentiation occurred, concomitant with upregulation of FOXL2 and WNT4 (Fig. 3). We propose a model in which the role of oestrogen is to modulate the subcellular localization of SOX9 (Fig. 5). This could be an underlying and ancestral mechanism that controls ovarian development in nonmammalian vertebrates. In the absence of oestrogen in developing male fetuses, SOX9 would become nuclear and initiate testicular differentiation. However, in those nonmammalian vertebrates destined to become females, expression of aromatase and the production of oestrogen could prevent the nuclear translocation of SOX9, thus actively blocking testicular development. In mammals, the retention of this mechanism is not an evolutionary remnant of past function, but may have been retained to ensure that SOX9 nuclear entry is suppressed in the mature ovary to maintain granulosa cell fate.

\section{Methods}

\section{Gonadal Culture}

$\mathrm{XY}$ gonadal ridges (gonad and mesonephros taken together) were cultured in pairs from late-stage male tammar wallaby fetuses. The tammar wallaby gonadal ridge first develops on day 21 of the 26.5-day gestation period [14]. Seminiferous cords do not form in testes until day $2 \mathrm{pp}$, and ovarian differentiation is first seen around day $8 \mathrm{pp}$ [14]. A total of 12 male fetuses were collected at day 25 of gestation, and pairs of gonads were isolated and placed, one into control media and the other into oestrogen media. Gonads were cultured for 5 days (120 hr) as previously described [12], with either Dulbecco's modified Eagle medium (DMEM)/ $10 \%$ fetal calf serum (FCS) $/ 50 \mathrm{mg} / \mathrm{ml}$ ampicillin (control) or with the addition of estradiol benzoate (to a final concentration of $100 \mathrm{ng} / \mathrm{ml}$ ). This dose was chosen to ensure sufficient oestrogen penetration into the cultured gonad. Estradiol benzoate was diluted in $100 \%$ ethanol at $1 \mathrm{mg} / \mathrm{ml}$, and an equivalent amount of ethanol (without estradiol) was added to control cultures. At the conclusion of the culture period, gonads were either fixed in $4 \%$ paraformaldehyde and processed for histology or snap-frozen for molecular analyses.

\section{Histology}

Two of the 12 control and two of the 12 oestrogen-treated XY cultured gonads were sectioned $(8 \mu \mathrm{m})$ and stained with Mallory's triple stain to highlight the basal lamina (bright blue) in the developing gonads, according to standard methods. 


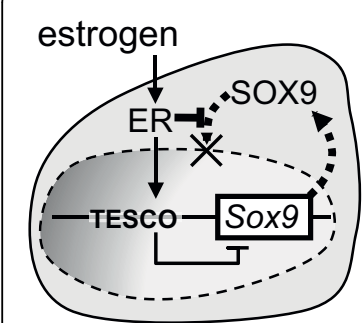

Granulosa cell fate

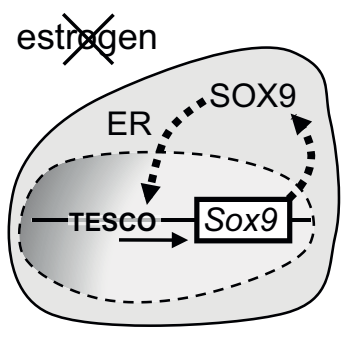

Sertoli cell fate
Figure 5 Model for the role of oestrogen and the gonadal determination pathway. In normal XY gonads, the somatic cells upregulate SRY, which in turn upregulates SOX9. SOX9 can then translocate to the nucleus and activate the expression of $A M H$ to ensure normal male urogenital development. In the presence of oestrogen, the bipotential somatic cell is instead directed into the granulosa cell pathway. SRY fails to upregulate, and any SOX9 protein produced fails to enter the nucleus. In the absence of nuclear SOX9, AMH fails to upregulate and ovarian genes (FOXL2 and WNT4) are activated. Exogenous oestrogen therefore has the ability to direct XY bipotential somatic cells to a granulosa cell fate. Oestrogen may act in a similar manner to maintain granulosa cell fate in mature eutherian ovaries, preventing basal levels of SOX9 protein from translocating to the nucleus and propagating its own upregulation.

\section{Immunohistochemistry}

Anti-SOX9 antibody (Ab5535; Chemicon) was used at 1:100 dilution. Slides were then incubated with goat anti-rabbit biotin-conjugated secondary antibody (Molecular Probes). The avidin-biotin complex (ABC) kit (Vector Laboratories) was used according to the manufacturer's instructions, and antibody binding was visualized with the AEC+ chromogen (Vector Laboratories). Negative controls were performed as described above with the omission of the primary antibody and an equivalent amount of nonspecific IgG from the same species. No staining was observed in negative controls. Sections were counterstained with haematoxylin.

\section{RNA extraction and CDNA synthesis}

RNA was extracted from gonads using the GenElute ${ }^{\mathrm{TM}}$ Mammalian Total RNA Miniprep Kit (Sigma) as per the manufacturer's instructions. Total RNA was DNase treated using the Turbo DNA free (Ambion) as per the manufacturer's instructions. Complementary DNA was produced using the Superscript III First Strand Synthesis System for reverse transcriptase (RT)-PCR (Invitrogen) to generate the first strand according to the manufacturer's instructions.

\section{Quantitative polymerase chain reaction}

qPCR was carried out using the Quantitect real-time master mix (Qiagen) on a Bio-Rad CFX96 PCR machine. The genes of interest were normalized against $\beta$-actin expression using the $\Delta \mathrm{CT}$ method described by Pfaffl [52] and taking primer efficiency into account. Standard $t$-tests (for sex reversal data; two-tailed, paired [gonad pairs; one cultured in oestrogen and the other in control media], for normal male profile; two-tailed, homoscedastic [comparing equal numbers of male and female gonads at different time points]) were used to compare the data sets using Microsoft Excel. For the normal gene expression profiles, data are shown relative to $\beta$-actin with individual gonads $(n \geq 5)$ at each developmental time point for each sex. For gonadal culture, the remaining 10 gonadal pairs that were cultured were analyzed (20 gonads; 10 control and 10 oestrogen-cultured). The expression was normalized relative to $\beta$-actin. Expression levels in control gonads were designated $100 \%$, and expression in the oestrogen-treated gonads expressed relative to control levels for each gene was examined. All real-time PCR reactions were subject to melt curve analysis and gel electrophoresis to check for single-product amplification. The primers chosen for amplification are listed in Additional file 4.

All experimental procedures conformed to Australian National Health and Medical Research Council (2004) guidelines and were approved by the University of Animal Experimentation Ethics Committees. Husbandry of tammar wallabies (Macropus eugenii) as well as aging and sexing of pouch young and fetuses were carried out as previously described [14].

\section{Additional material}

Additional file 1: Statistical difference between male and female
data points shown in Figure $1 . P$ values (from $t$-tests) are listed for all
data points shown in the normal expression profiles for SOX9, AMH, FGF9,
FOXL2, FST, RSPO1, WNT4. Gene name is given in the top left hand corner
of each data set. Column 2 shows the stage of development; $d=$ day of
gestation, D = postnatal day. Column 3 shows the $P$ value from a two
tailed, homoscedastic $t$-test (conducted in Microsoft Excel). Significant
values ( $P \leq 0.05$ ) are highlighted in yellow. The bottom row (combined
M (male) $\vee$ F (female)) shows the $P$ values for the entire male versus
female data set combined across the time period shown. SOX9, AMH,
FOXL2 and FST showed the greatest difference between testes and
ovaries. WNT4 was significantly higher in females than males over the
entire period examined, but was not significantly higher at any given
time point.
Additional file 2: Raw expression data for qPCR analysis of the
oestrogen-treated and control culture gonads. Graphs show
expression relative to beta-actin (house keeping control gene) that
shows high levels of expression. Small bars represent a small difference
between target gene expression and that of beta-actin (thus, represent
high expression values) while large bars show a greater difference
between target gene levels and beta-actin (thus, representing low
expression values). Error bars show one standard deviation either side of
the mean.
Additional file 3: Sox9 distribution in the bipotential gonad. SOX9
protein was examined in the day 25 fetal XY gonad to determine its
distribution at the start of the culture period. At this time, SOX9 was
already localized in the nuclei (black arrowhead) of many somatic cells,
but some weak cytoplasmic staining (red arrowhead) also remained.
data points shown in Figure 1. $P$ values (from $t$-tests) are listed for all data points shown in the normal expression profiles for SOX9, AMH, FGF9, FOXL2, FST, RSPO1, WNT4. Gene name is given in the top left hand corner of each data set. Column 2 shows the stage of development; $d=$ day of gestation, $\mathrm{D}=$ postnatal day. Column 3 shows the $P$ value from a two values $(P \leq 0.05)$ are highlighted in yellow. The bottom row (combined $M$ (male) v $F$ (female)) shows the $P$ values for the entire male versus ovaries. WNT4 was significantly higher in females than males over the entire period examined, but was not significantly higher at any given time point.

Additional file 2: Raw expression data for qPCR analysis of the shows high levels of expression. Small bars represent a small difference between target gene expression and that of beta-actin (thus, represent expression values). Error bars show one standard deviation either side of

protein was examined in the day 25 fetal XY gonad to determine its already localized in the nuclei (black arrowhead) of many somatic cells, but some weak cytoplasmic staining (red arrowhead) also remained. 
Additional file 4: Primers used. Primers used in quantitative PCR reactions are listed in $5^{\prime}$ to $3^{\prime}$ orientation.

Additional file 5: Raw expression data for qPCR analysis of the normal gene profiles shown in Figure 1. Mean delta $\mathrm{Ct}$ values and the standard deviation (std-dev) for each data point shown in Figure 1. The housekeeping gene $\beta$-actin shows high levels of expression so most delta Ct values are negative. The left column represents data points from the male profile and the right column represents data points from the female profile. Gene names are indicated in the top left corner of each table. Graphed data is log transformed and shown relative to beta actin in Figure 1.

\section{Acknowledgements}

We thank Ms. K. Martin and Mr. S. Brownlees for assistance with animal handling, Ms. S Osborn for assistance with culture and Ms. A. Santos de Medeiros for assistance with sample preparation. We are grateful to Profs. R. Lovell-Badge and J. D. Wilson for helpful comments on the manuscript. This work was supported by a project grant \#454367 to AJP, MBR and GS, an RD Wright fellowship from the National Health and Medical Research council to AJP and an Australian Research Council Federation Fellowship to MBR.

\section{Author details}

Department of Molecular and Cellular Biology, University of Connecticut, Storrs, CT 06260, USA. ²Department of Zoology, The University of Melbourne, Melbourne, Victoria 3010, Australia.

\section{Authors' contributions}

AJP and MBR conceived the study. All authors performed aspects of the research. AJP analyzed data. The manuscript was prepared by all authors.

Received: 10 June 2010 Accepted: 31 August 2010

Published: 31 August 2010

\section{References}

1. Ramsey M, Crews D: Steroid signaling and temperature-dependent sex determination: reviewing the evidence for early action of estrogen during ovarian determination in turtles. Semin Cell Dev Biol 2009, 20:283-292.

2. Couse JF, Korach KS: Estrogen receptor null mice: what have we learned and where will they lead us? Endocr Rev 1999, 20:358-417.

3. Bagheri-Fam S, Sinclair AH, Koopman P, Harley VR: Conserved regulatory modules in the Sox9 testis-specific enhancer predict roles for SOX TCF/ LEF Forkhead DMRT and GATA proteins in vertebrate sex determination. Int J Biochem Cell Biol 2009, 42:472-477.

4. Morais da Silva S, Hacker A, Harley V, Goodfellow P, Swain A, LovellBadge R: Sox9 expression during gonadal development implies a conserved role for the gene in testis differentiation in mammals and birds. Nat Genet 1996, 14:62-68

5. De Santa Barbara P, Moniot B, Poulat F, Berta P: Expression and subcellular localization of SF-1 SOX9 WT1 and AMH proteins during early human testicular development. Dev Dyn 2000, 217:293-298.

6. El Jamil A, Kanhoush R, Magre S, Boizet-Bonhoure B, Penrad-Mobayed M: Sex-specific expression of SOX9 during gonadogenesis in the amphibian Xenopus tropicalis. Dev Dyn 2008, 237:2996-3005.

7. Britt KL, Stanton PG, Misso M, Simpson ER, Findlay JK: The effects of estrogen on the expression of genes underlying the differentiation of somatic cells in the murine gonad. Endocrinology 2004, 145:3950-3960.

8. Short RV: New thoughts on sex determination and differentiation. Glaxo 1974, 39:5-20-59-60.

9. Mittwoch U: Male sexual development in "a sea of oestrogen". Lancet 1993, 342:123-124.

10. Greco TL, Furlow JD, Duello TM, Gorski J: Immunodetection of estrogen receptors in fetal and neonatal male mouse reproductive tracts. Endocrinology 1992, 130:421-9.

11. Gould DA, Moscoso GJ, Young MP, Barton DP: Human first trimester fetal ovaries express oncofetal antigens and steroid receptors. J Soc Gynecol Investig 2000, 7:131-138.
12. Calatayud NE, Pask AJ, Shaw G, Renfree MB: Ontogeny of the oestrogen receptors ESR1 and ESR2 during gonadal development in the tammar wallaby Macropus eugenii. Reproduction 2010, 139:599-611.

13. Slikker W Jr, Bailey JR, Newport D, Lipe GW, Hill DE: Placental transfer and metabolism of 17 alpha-ethynylestradiol-17 beta and estradiol-17 beta in the rhesus monkey. J Pharmacol Exp Ther 1982, 223:483-9.

14. Renfree MB, O W-S, Short RV, Shaw G: Sexual differentiation of the urogenital system of the fetal and neonatal tammar wallaby Macropus eugenii. Anat Embryol 1996, 194:111-134.

15. Burns RK: Effects of testosterone propionate on sex differentiation in pouch young of opossum. Proc Soc Exp Biol Med 1939, 41:60-62.

16. Burns RK: The differentiation of sex in the opossum (Didelphis virginiana) and its modification by the male hormone testosterone propionate. Morphol 1939, 65:79-119.

17. Burns RK: Sex and Internal Secretions.Edited by: Young WC. Baltimore: Williams 1961:1:76-158.

18. Coveney D, Shaw G, Renfree MB: Estrogen-induced gonadal sex reversal in the tammar wallaby. Biol Reprod 2001, 65:613-621.

19. Coveney D, Shaw G, Renfree MB: Effects of oestrogen treatment on testicular descent inguinal closure and prostatic development in a male marsupial Macropus eugenii. Reproduction 2002, 124:73-83.

20. Shaw G, Renfree MB, Short RV, O WS: Experimental manipulation of sexual differentiation in wallaby pouch young treated with exogenous steroids. Development 1988, 104:689-701.

21. Renfree MB, Coveney D, Shaw G: The influence of estrogen on the developing male marsupial. Reprod Fertil Dev 2001, 13:231-240

22. Hiramatsu R, Matoba S, Kanai-Azuma M, Tsunekawa N, Katoh-Fukui Y, Kurohmaru M, Morohashi K, Wilhelm D, Koopman P, Kanai Y: A critical time window of Sry action in gonadal sex determination in mice. Development 2009, 136:129-138.

23. Crews $D$, Cantú $A R$, Bergeron JM, Rhen $T$ : The relative effectiveness of androstenedione testosterone and estrone precursors to estradiol in sex reversal in the red-eared slider (Trachemys scripta): a turtle with temperature-dependent sex determination. Gen Comp Endocrinol 1995, 100:119-127.

24. Harry JL, Koopman P, Brennan FE, Graves JA, Renfree MB: Widespread expression of the testis-determining gene SRY in a marsupial. Nat Genet 1995, 11:347-349.

25. Pask AJ, Harry JL, Graves JA, O’Neill RJ, Layfield SL, Shaw G, Renfree MB: SOX9 has both conserved and novel roles in marsupial sexual differentiation. Genesis 2002, 33:131-139.

26. Rey $R$, Josso N: Regulation of testicular anti-Mullerian hormone secretion. Eur J Endocrinol 1996, 135:144-152.

27. Pask AJ, Whitworth DJ, Mao CA, Wei KJ, Sankovic N, Graves JA, Shaw G, Renfree MB, Behringer RR: Marsupial anti-Müllerian hormone gene structure regulatory elements and expression. Biol Reprod 2004, 70:160-167.

28. Schmahl J, Capel B: Cell proliferation is necessary for the determination of male fate in the gonad. Dev Biol 2003, 258:264-276.

29. Whitworth DJ, Shaw G, Renfree MB: Müllerian duct regression in a marsupial, the tammar wallaby. Anat Embryol (Berl) 1997, 196:39-46.

30. Kim Y, Kobayashi A, Sekido R, DiNapoli L, Brennan J, Chaboissier MC, Poulat F, Behringer RR, Lovell-Badge R, Capel B: Fgf9 and Wnt4 act as antagonistic signals to regulate mammalian sex determination. PLOS Biol 2006, 4:e187.

31. Yao HH, Matzuk MM, Jorgez CJ, Menke DB, Page DC, Swain A, Capel B: Follistatin operates downstream of Wnt4 in mammalian ovary organogenesis. Dev Dyn 2004, 230:210-215.

32. Chassot AA, Gregoire EP, Magliano M, Lavery R, Chaboissier MC: Genetics of ovarian differentiation: Rspo1, a major player. Sex Dev 2008, 2:219-227.

33. Uhlenhaut NH, Jakob S, Anlag K, Eisenberger T, Sekido R, Kress J, Treier AC, Klugmann C, Klasen C, Holter NI, Riethmacher D, Schütz G, Cooney AJ, Lovell-Badge $\mathrm{R}$, Treier M: Somatic sex reprogramming of adult ovaries to testes by FOXL2 ablation. Cell 2009, 139:1130-1142.

34. Hacker A, Capel B, Goodfellow P, Lovell-Badge R: Expression of Sry, the mouse sex determining gene. Development 1995, 121:1603-1614.

35. Bullejos $M$, Koopman P: Spatially dynamic expression of Sry in mouse genital ridges. Dev Dyn 2001, 221:201-205.

36. Hanley NA, Hagan DM, Clement-Jones M, Ball SG, Strachan T, Salas-Cortés L, McElreavey K, Lindsay S, Robson S, Bullen P, Ostrer H, Wilson DI: SRY SOX9 
and DAX1 expression patterns during human sex determination and gonadal development. Mech Dev 2000, 91:403-407.

37. Sekido R, Lovell-Badge R: Sex determination involves synergistic action of SRY and SF1 on a specific Sox9 enhancer. Nature 2008, 453:930-934.

38. Garcia-Ortiz JE, Pelosi E, Omari S, Nedorezov T, Piao Y, Karmazin J, Uda M, Cao A, Cole SW, Forabosco A, Schlessinger D, Ottolenghi C: Foxl2 functions in sex determination and histogenesis throughout mouse ovary development. BMC Dev Biol 2009, 9:36.

39. Vidal VP, Chaboissier MC, de Rooij DG, Schedl A: Sox9 induces testis development in XX transgenic mice. Nat Genet 2001, 28:216-217.

40. Bishop CE, Whitworth DJ, Qin Y, Agoulnik Al, Agoulnik IU, Harrison WR, Behringer RR, Overbeek PA: A transgenic insertion upstream of sox9 is associated with dominant XX sex reversal in the mouse. Nat Genet 2000, 26:490-494.

41. Sim H, Argentaro A, Harley VR: Boys, girls and shuttling of SRY and SOX9. Trends Endocrinol Metab 2008, 19:213-222.

42. Malki S, Boizet-Bonhoure B, Poulat F: Shuttling of SOX proteins. Int $J$ Biochem Cell Biol 2010, 42:411-416.

43. Shoemaker C, Ramsey M, Queen J, Crews D: Expression of Sox9 Mis and Dmrt1 in the gonad of a species with temperature-dependent sex determination. Dev Dyn 2007, 236:1055-1063.

44. Wilhelm D, Martinson F, Bradford S, Wilson MJ, Combes AN, Beverdam A, Bowles J, Mizusaki H, Koopman P: Sertoli cell differentiation is induced both cell-autonomously and through prostaglandin signaling during mammalian sex determination. Dev Biol 2005, 287:111-124.

45. Barske LA, Capel B: Estrogen represses SOX9 during sex determination in the red-eared slider turtle Trachemys scripta. Dev Biol 2010, 341:305-314.

46. Arango NA, Lovell-Badge R, Behringer RR: Targeted mutagenesis of the endogenous mouse Mis gene promoter: in vivo definition of genetic pathways of vertebrate sexual development. Cell 1999, 99:409-419.

47. Notarnicola C, Malki S, Berta P, Poulat F, Boizet-Bonhoure B: Transient expression of SOX9 protein during follicular development in the adult mouse ovary. Gene Expr Patterns 2006, 6:695-702.

48. Britt KL, Kerr J, O'Donnell L, Jones ME, Drummond AE: Estrogen regulates development of the somatic cell phenotype in the eutherian ovary. FASEB J 2002, 16:1389-1397.

49. Akiyama H, Kamitani T, Yang X, Kandyil R, Bridgewater LC, Fellous M, MoriAkiyama $Y$, de Crombrugghe B: The transcription factor Sox 9 is degraded by the ubiquitin-proteasome system and stabilized by a mutation in a ubiquitin-target site. Matrix Biol 2005, 23:499-505.

50. Hattori T, Eberspaecher H, Lu J, Zhang R, Nishida T, Kahyo T, Yasuda H, de Crombrugghe B: Interactions between PIAS proteins and SOX9 result in an increase in the cellular concentrations of SOX9. J Biol Chem 2006, 281:14417-14428.

51. Wu H, Sun L, Zhang Y, Chen Y, Shi B, Li R, Wang Y, Liang J, Fan D, Wu G, Wang D, Li S, Shang Y: Coordinated regulation of AIB1 transcriptional activity by sumoylation and phosphorylation. J Biol Chem 2006, 281:21848-21856.

52. Pfaffl MW: A new mathematical model for relative quantification in realtime RT-PCR. Nucleic Acids Res 2001, 29:e45.

doi:10.1186/1741-7007-8-113

Cite this article as: Pask et al:: Oestrogen blocks the nuclear entry of SOX9 in the developing gonad of a marsupial mammal. BMC Biology $20108: 113$

\section{Submit your next manuscript to BioMed Central and take full advantage of:}

- Convenient online submission

- Thorough peer review

- No space constraints or color figure charges

- Immediate publication on acceptance

- Inclusion in PubMed, CAS, Scopus and Google Scholar

- Research which is freely available for redistribution

Submit your manuscript at www.biomedcentral.com/submit
Biomed Central 